Journal of Engineering and Applied Sciences 15 (2): 398-409, 2020

ISSN: 1816-949X

(C) Medwell Journals, 2020

\title{
Influence of Organizational Culture, Organizational Trust and Self-Efficacy on Knowledge Sharing Behavior by Mediating Organizational Commitments Study on Auditors of District/City Inspectorates in East Java Province
}

\author{
Didi Wahyudi, Ubud Salim, Atim Djazuli and Rofiaty \\ Faculty of Economic and Business, University of Brawijaya, Malang, Indonesia
}

\begin{abstract}
The role of individual's knowledge on the development of an organization demonstrates pivotal lieu for both public and private sector organizations. The needs for public sector workers who posses knowledge encourage awareness on the importance of knowledge acquisition particularly for the knowledge mastered by each of individual in the organization. Employees involved in knowledge sharing activity will boost performance and productivity. The process of knowledge sharing in an organization is driven by several factors including organizational culture, organizational trust, self efficacy and organizational commitment. This research aims to investigate and reveal how organizational commitment as the mediating variable on the relationship among organizational culture, organizational trust and self efficacy toward knowledge sharing behavior variables. This research is conducted at Inspectorate of local governments in East Java province which took 268 respondents as its sample by using Partial Least Square analysis (Warp PLSV.5). The result shows that organizational culture, self efficacy and organizational commitment influence knowledge sharing behavior; yet, organizational trust does not affect knowledge sharing behavior. It indicates that greater level of organizational culture, self efficacy and organizational commitment in public sector will result in greater knowledge sharing behavior; however, higher level of organizational trust does not increase knowledge sharing behavior in public sector context. The finding of this research proves that organizational commitment is able to partially mediate the effects of organizational culture and self efficacy on knowledge sharing behavior; further, organizational commitment has a function as a full mediation on the effect of organizational trust on knowledge sharing behavior.
\end{abstract}

Key words: Organizational culture, organizational trust, self-efficacy, organizational commitment, knowledge sharing behavior, mediation

\section{INTRODUCTION}

One of the challenges that must be taken into account in the world is the world in the world of VUCA (Mack et al., 2015). VUCA terminology which stands for volatility, uncertainty, complexity and ambiguity is the most common thing in the world today. Volatility is a very fast dynamics, uncertainty that is interpreted as a predictability error on the issues and events that occur, complexity that is the existence of interference and flexibility while ambiguity is defined as various forms of meaning and meaning that blend from various conditions.

Many organizations are used to survive and live in the nature of the VUCA including organizations in the public sector. The Inspectorate as the Government's Internal Supervision Apparatus (APIP) which is a government institution engaged in supervision and also the multidimensional tourism dynamics. The existence of an organization at the government/city level is not permitted. With the wider, heavier and complex problems of governance and development, it will be increasingly important and strategic, especially with the strengthening of good governance and the eradication of corruption, collusion and nepotism at all levels of government.

Together with the reform of state finance with the enactment of the package of Law No. 17 of 2003 concerning State Finance which is the basis which among other things, implies the paradigm concept of the internal supervision apparatus. The original paradigm that positioned the supervisory apparatus as a guard dog through audits and other attestations has shifted to an analyzer in the office's internal environment, consultation and other non-audit/attestation assignments.

Under these conditions, the organization is used to determine the level of security in the front line of supervision with the new paradigm above. A combination of formal and informal efforts undertaken to train and equip auditors with knowledge and skills that are appropriate to their roles and responsibilities as policies that are not sufficient enough. In terms of quantity and quality of switching still occur.

Development of auditor capacity of internal audit apparatus in the internal audit capablity model. The model 
groups APIP organizations into five capability levels. At the first (initial) level, APIPP has not been able to provide functions in accordance with the rules and has not been able to prevent corruption while at the peak level (optimization), APIP Model has become a project.

The 2014-2019 Medium Term Development Plan targets $85 \%$ of the internal supervision apparatus to have level 2 capability. Until now most of the APIP organizations in East Java province are still below level 2 of the five levels of APIP capability. At the organizational unit level, APIP has not been able to guarantee the governance process in accordance with the provisions of the regulations in their respective regions. In addition, the APIP organizational unit which is below level 2 has not been able to detect corruption. This condition is still far from expectations where the APIP organization is expected to be able to produce a role as an agent of change.

Achievement levels APIP capability cannot be used from the performance determined by the APIP organization. Management of intangible assets knowledge that exists in the auditor as knowledge workers (knowledge workers) that are different from tangible assets in general. An organizational paradigm is needed that sees these aspects directly and proportionally.

Changes in the organizational paradigm must be followed by the application of appropriate strategies. Ikujiro Nonaka reminded that in an economy where the only certainty is uncertainty, one source of lasting competitive advantage is knowledge (Nonaka and Takeuchi, 1995). Among management practitioners, knowledge management has become one of the hot topics discussed because every day management practitioners deal with a series of data and information, both quantitative and qualitative. It's just that not all data and information can be useful. In order to make it valuable to the organization, data and information must be explored and explored, so that, it becomes knowledge that can be used for decision making.

Although, the theory and practice have been developed for more than two decades, the idea of knowledge management is still in debate. Knowledge management is also defined as knowledge-based management which is a managerial philosophy that focuses on knowledge as a strategic resource. Although, knowledge cannot be managed as conventional assets, it is still possible to manage intellectual assets, capabilities and organizational processes by focusing on developing knowledge and learning (Dalkir, 2011).

Knowledge can be defined as something that is believed and justified (Nonaka, 1994) both individually and collectively within the organization. In the process of implementing new knowledge, individuals and organizations experience changes that demand a shift in thinking and behaving. The process can involve dissemination of instilling organizational norms and assumptions in the minds of employees (Husain et al., 2015). In addition, it can also result in changes in procedures, responsibilities and norms (Chen, 2011; Davenport and Prusak, 1998; Holt, 2007). For a major change to be successful, it is necessary to have an organizational culture characteristic inherent in the organization (Dirani, 2009).

Knowledge sharing behavior is one form of developing aspects of human resources in the practice of knowledge management processes. Many studies related to knowledge management emphasize operational aspects and knowledge management technologies but aspects of human behavior can be used as an approach that can contribute to knowledge management. Therefore, it is important for researchers to explore the relationships of people management and the contribution of knowledge management, especially, related to knowledge sharing behavior.

Knowledge sharing is defined by Lin (2007) as a culture of social interaction including the exchange of knowledge, experience and expertise through organizational unity. Folorunso et al. (2014) also stated that knowledge sharing is considered as an informal communication process that involves sharing knowledge between workers where organizational trust determines the running of the communication process. It was further stated that members in the organization were better prepared with skills and knowledge when they were involved in sharing knowledge. Some members of organizations and managers assess the practice of sharing knowledge among employees will make individual work easier and save individual time for more substantive tasks. However, it is difficult to enforce knowledge sharing because knowledge is created and stored in organizational members (Moon and Lee, 2014).

Based on a study from Hislop (2003) concluded that the most significant factor influencing knowledge sharing is employee attitudes. In some cases, employee attitudes can inhibit knowledge sharing behavior because knowledge sharing behavior is considered individualistic behavior (Bock and Kim, 2002). It is important to understand how the results of individual attitudes and behaviors may have different effects on employee knowledge sharing behavior. Some of the findings of previous studies show differences in results regarding these attitudes and behaviors.

In the theory of organizational commitment, Detert et al. (2007) and Aizpurua et al. (2011) state that in order to meet socio-emotional needs and to assess the benefits of work effort increases, employees form a general perception of the extent to which the organization values its contribution and care for their welfare. These organizational commitments will increase employee's feelings regarding the obligation to help the organization achieve its goals, affective commitment to the organization and the hope that improved performance will be appropriately valued. 
There are differences in the results of the findings of several previous studies that link organizational culture, organizational trust and self-efficacy to knowledge sharing behavior. This study will try to focus on the factors that influence knowledge sharing behavior at the individual and organizational level in the context of workplace organization, taking into account differences in the results of the findings of several previous studies.

Research that explores the problem of knowledge sharing behavior has been widely carried out but which specifically integrates it with organizational commitment is still little done for the context of the public sector in Indonesia, especially in the auditor's environment of government intelligence. This research attempts to fill the gap of previous research in the form of inconsistencies in research results regarding the influence of organizational culture, organizational trust and direct self-efficacy on knowledge sharing behavior. This research model will involve mediating variables of organizational commitment. The results of this study are expected to be used to clarify how the mechanism of influence of organizational culture, organizational trust and self-efficacy on knowledge sharing behavior.

Based on the explanation above, the researchers are interested in conducting a study of how organizational culture, organizational trust and self-efficacy relate to knowledge sharing behavior by mediating organizational commitment in district/city inspectorate organizations throughout East Java province.

Theory and hypothesis: Social learning theory (social learning theory) as the grand theory used in this study describes human behavior in terms of reciprocal interaction (recyprocal) that is continuous (continuous) between cognitive factors, behavior and environmental factors. Humans and their environment are mutually decisive factors (Bandura, 1977). According to Bandura, individuals learn information which is processed cognitively and acts based on the information obtained. The basic assumption in this theory states that most of the individual behavior is obtained from learning outcomes through observations of behavior displayed by other individuals who become models or people who are considered to have more value than others. This learning process is called observational learning.

In view of the social learning theory of expected behavior is closely related to the social context in which the behavior is applied. Knowledge sharing is one step in knowledge management to provide opportunities for members of an organization group, agency or company to share knowledge, techniques, experiences and ideas they have with other members. Knowledge sharing can only be done if each member has a wide opportunity to express their opinions, ideas, criticisms and comments to other members.
Organizational culture will encourage individuals to behave in certain organizations. Culture can affect all activities in the organization, both ways of looking at work, working with colleagues and looking into the future (Cropanzano and Mitchell, 2005). Meanwhile Hofstede (1994) views organizational culture as a pattern of thought, feelings and actions of a social group which distinguishes it from other social groups. It can be said that organizational culture is the norms and habits that are accepted as a truth by all people in the organization.

Trust or trust is one of the most valued values in social relations between people. Trust is a sense of trust that someone has toward others. This trust is based on integrity, reliability and attention. In organizations, trust has an impact on the formation of behavior. Organizational trust as the belief of an individual that the person who is trusted will take actions that are beneficial for him.

Self-efficacy (self-efficacy) is defined by Bandura as a belief in the ability of yourself to organize and move the sources of action needed to manage future situations Bandura. Wood and Bandura emphasize that people are actually "products and producers of the environment". While Pejares explains, self-efficacy is a determinant in the completion of a task. Therefore, a person in feeling his effectiveness will vary depending on the task he receives. The ability of generative self-efficacy has been proven to be able to manage changes in the environment.

Organizational commitment is a multi-dimensional construct that describes the psychological conditions of workers who are able to provide an overview of how the relationship between individuals and their organizations. Organizational commitment relates to perceptions of warmth, supportive organizational climate and the desire to help as a good team member (Luthans, 2006; Roberts, 2000). Husselid and Day state that employee commitment can reduce the desire to break away from the organization and tend to show high involvement in the form of attitudes and behavior.

The influence of organizational culture on knowledge sharing behavior: Capability and performance of an organization is largely determined by the presence or absence of core competencies in the organization as a basis for producing competitive goods or services. To be able to realize this requires a continuous learning process that integrates active abilities and technology in the organization. Without an adequate learning culture, it is difficult for an organization to develop, therefore the creation of a learning climate for each individual in an organization will be the basis for the emergence of learning organizations. 
Ghina (2012) provides the view that the key to the strength of organizational learning is an organization that seeks to increase its capacity to make changes by providing opportunities for its members to combine quality initiatives with the quality of work life, create free space for learning, encourage collaboration, develop supervision and create continuous learning opportunities in accordance with the norms and values shared. In relation to knowledge sharing behavior, previous research conducted by Sorakraikitikul and Siengthai, Jo and Joo (2011) and Jusain confirms the fact that it can be hypothesized that:

- $\mathrm{H}_{1}$ : strengthening organizational culture will be able to improve knowledge sharing behavior

Influence of organizational trust on knowledge sharing behavior: Knowledge Sharing is one step in knowledge management to provide opportunities for members of an organization group, agency or company to share knowledge, techniques, experiences and ideas they have with other members. Knowledge sharing can only be done if each member has a wide opportunity and psychologically feels the existence of organizational trust in expressing opinions, ideas, criticisms and comments to other members.

Organizational trust influences knowledge sharing as an activity of the transfer or dissemination of knowledge that includes explicit and implicit knowledge from one person, group or organization with another that requires mutual trust. Previous research conducted by Song and Kolb (2013) show that organizational trust has a significant effect on knowledge sharing behavior:

- $\mathrm{H}_{2}$ : strengthening organizational trust will be able to improve knowledge sharing behavior

Effect of self-efficacy on knowledge sharing behavior: Knowledge sharing behavior is a multidimensional construct that leads to the involvement of workers in the organization and a constant process indicates individual confidence in contributing to the process of knowledge management in the organization. Some studies reveal that self-efficacy has a positive effect on knowledge sharing behavior (Tuan, 2016). Furthermore, Balay (2012), Aghaei et al. (2012) revealed that self-efficacy contributes positively to knowledge sharing behavior, so that, the following hypotheses can be prepared:

- $\mathrm{H}_{3}$ : strengthening self-efficacy will be able to improve knowledge sharing behavior
The effect of organizational culture on organizational commitment: Organizational culture as norms and habits that are accepted as a truth by all people in the organization if managed properly will foster the expected organizational commitment. Given the organizational culture as a pattern of thought, feelings and actions of a social group which distinguishes it from other social groups, the uniqueness is also a factor that influences the growth of commitment to the organization.

With the shared values and a guide for all members of the organization to think, act and behave, the commitment to the organization can be grown. Previous research conducted by Islam et al. (2013, 2011, 2015), and Joo and Park (2010) show that organizational culture has a significant effect on organizational commitment, so, that hypotheses can be prepared as follows:

- $\mathrm{H}_{4}$ : strengthening organizational culture will be able to increase organizational commitment

Effect of organizational trust on organizational commitment: In an organizational perspective, the existence of organizational trust in which each member feels a belief in expressing opinions, ideas, criticisms and comments to other members of the organization can foster a commitment to the organization. Organizational trust can increase organizational commitment as studied by Islam et al. (2015), Han et al. (2016), Jaiswal and Dhar (2016), Gholami and Hashmi and Naqvi which show that organizational trust has a significant effect on organizational commitment, so that, hypoetsis can be arranged as follows:

- $\mathrm{H}_{5}=$ Strengthening organizational trust will be able to increase organizational commitment

Effect of self-efficacy on organizational commitment: Confidence in the ability to perform certain tasks that encourage members of a group of organizations, agencies or companies to interact with each other to share knowledge, techniques, experiences and ideas they have with other members in the public sector. In this regard, self-efficacy found in public sector organizations is seen as being able to encourage increased organizational commitment. Previous research conducted by Perdosipour and Montazeri and Shrestha and Mishra shows that self-efficacy has a significant effect on organizational commitment, so that, the following hypotheses can be arranged:

- $\mathrm{H}_{6}$ : strengthening self-efficacy will be able to increase organizational commitment 
Effect of organizational commitment to knowledge sharing behavior: Knowledge Sharing is one step in knowledge management to provide an opportunity for members of an organization group, agency or company to share knowledge, techniques, experiences and ideas they have with other members. In the perspective of the learning organization, knowledge sharing can only be done if each member has a broad opportunity to express opinions, ideas, criticisms and comments to other members. The opportunity is more open if there is adequate organizational commitment.

Knowledge sharing is an activity of the transfer or dissemination of knowledge that includes explicit and implicit knowledge from one person, group or organization with the other influenced by organizational commitment owned by members of the organization. Previous research conducted by Anvari et al. (2014), Muneer et al. (2014), Shirazi et al. (2014) and Chang et al. (2013) show that organizational commitment has a significant effect on knowledge sharing behavior, so that the following hypotheses can be arranged:

- $\mathrm{H}_{7}=$ Strengthening organizational commitment will be able to improve knowledge sharing behavior

Mediation role of organizational commitments: Organizational commitment can be seen to increase the factors that influence the expected growth of behavior in the organization. Affective commitment, ongoing commitment and normative commitment describe emotional attachment, identification with the organization and involvement of someone in an organization. This commitment is influenced and or developed, if involvement in the organization proves to be a satisfying experience that can provide opportunities to do work better or produce opportunities to gain valuable skills for the improvement of expected behavior.

- $\mathrm{H}_{8}=$ Strengthening organizational culture will be able to improve knowledge sharing behavior through strengthening organizational commitment

- $\mathrm{H}_{9}=$ Strengthening organizational trust will be able to improve knowledge sharing behavior through strengthening organizational commitment

- $\mathrm{H}_{10}=$ Strengthening self-efficacy will be able to improve knowledge sharing behavior through stregthening organizational commitment (Fig. 1)

Basic influence between variables: Al-Alawi et al. (2007); Islam et al. (2011); Mehrabi et al. (2013); Sanjaghi (2013); Ahoozadeha and Naderi (2014);

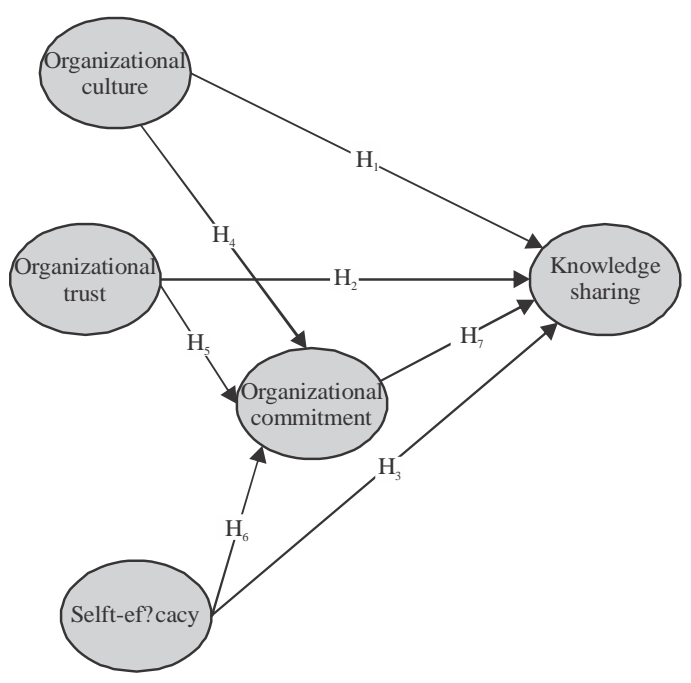

Fig. 1: Framework for research concepts

Ting et al. (2016); Baruji et al. (2016). Hassandoust (2011); Ho et al. (2012); Kuo (2013); Swift and Hwang (2013); Jain et al. (2015); Rutten et al. (2016). Fathi et al. (2010); Iqbal et al. (2011); Chen et al. (2012); Zhang and Ng (2012); Shaari et al. (2014); Hosseini et al. (2014); Ghina (2012).

Ooi and Arumugam (2006), Boon and Arumugam Ghina (2012), Momeni et al. (2012), Ghorbanhosseini (2013), Mitic etal. (2016), Bastug et al. (2016), Akhtar et al. (2013), Agarwal and Mishra (2016). Chang et al. (2013), Anvari et al. (2014), Shirazi et al. (2014) and Muneer et al. (2014).

\section{MATERIALS AND METHODS}

This research was carried out by survey method to auditors of district/city Inspectorates in East Java province. Questionnaires collected were 268 respondents. The construct measurement of the research was carried out through the measurement scale of reflective indicators using Likert scale techniques. The construction of organizational culture is measured using 5 dimensions and 17 items (Ghina, 2012). The construct of organizational trust is measured using 5 dimensions with 11 items (Jain et al., 2015), self-efficacy is measured using 3 dimensions with 9 items (Bandura, 1986), organizational commitment is measured using 2 dimensions with 6 items (Meyer and Allen, 1991) and knowledge sharing behavior was measured using 3 dimensions with 12 items Darroch, 2005; De Vries et al., 2006). The analysis tool used is Partial Least Square Structural Equation Model (PLS SEM) with WrapPLS Software. 
Table 1: Research gap

\begin{tabular}{|c|c|c|}
\hline Research/Gap & Researcher & Findings \\
\hline \multicolumn{3}{|l|}{ Gap 1} \\
\hline \multirow[t]{2}{*}{$\begin{array}{l}\text { There is a research gap between } \\
\text { organizational culture variables } \\
\text { on knowledge sharing behavior } \\
\text { influence }\end{array}$} & $\begin{array}{l}\text { Al-Alawi et al. (2007), Islam et al. (2011), } \\
\text { Mehrabi et al. (2013), Sanjaghi et al. (2013), } \\
\text { Ahoozadeha dan Naderi (2044), Ting et al. (2016), } \\
\text { Baruji et al. (2016) }\end{array}$ & $\begin{array}{l}\text { Organizational culture has a significant } \\
\text { effect on knowledge sharing behavior }\end{array}$ \\
\hline & Rad, Giri & $\begin{array}{l}\text { Organizational culture does not } \\
\text { significantly knowledge sharing behavior }\end{array}$ \\
\hline \multicolumn{3}{|r|}{$e_{0}$} \\
\hline $\begin{array}{l}\text { There is a research gap between } \\
\text { the variables of organizational } \\
\text { trust in knowledge sharing }\end{array}$ & $\begin{array}{l}\text { Hassandoust et al. (2011), Ho et al. } \\
\text { (2012), Kuo (2013), Swift and Hwang (2013) } \\
\text { Jain et al. (2015), Rutten et al. (2016) }\end{array}$ & $\begin{array}{l}\text { Organizational culture does not significantly } \\
\text { influence knowledge sharing behavior }\end{array}$ \\
\hline behavior & $\begin{array}{l}\text { Chiu et al. (2006), Wang dan Wei (2011), } \\
\text { Yeo dan Gold }\end{array}$ & $\begin{array}{l}\text { Organizational trust does not significantly } \\
\text { influence knowledge sharing behavior }\end{array}$ \\
\hline \multirow[t]{2}{*}{$\begin{array}{l}\text { Gap } 3 \\
\text { There is a research gap between } \\
\text { the variables of self-efficacy and } \\
\text { knowledge sharing behavior }\end{array}$} & $\begin{array}{l}\text { Fathi et al. (2011), lobal, Chen et al. } \\
\text { (2012), Zhang and Ng (2012), Shaari et al. (2014), } \\
\text { Hosseini et al. (2014),Yilmaz (2016) }\end{array}$ & $\begin{array}{l}\text { Self-efficacy has a significant positive } \\
\text { effect on knowledge sharing behavior }\end{array}$ \\
\hline & Chen et al. (2012), Kanaan & $\begin{array}{l}\text { Self-efficacy does not significantly affect } \\
\text { knowledge sharing behavior }\end{array}$ \\
\hline
\end{tabular}

\section{RESULTS AND DISCUSSION}

Outer model/measurement model: The measurement model is a model with calculations based on calculations using the WarpPLS program. The method used is confirmatory factor analysis where using this tool will be known the indicators really can explain a construct. The purpose of the measurement model is to describe how well the indicators in this study can be used as an instrument in measuring latent variables.

Evaluation of the validity of the 1st order model measurement model can be done by looking at the estimated results of the factor load. A variable is said to be validity if the standard factor load value is $\geq 0.6$ and the value of Average Variance Extracted (AVE) is $\geq 0.5$. While the evaluation of the reliability of the PLS measurement model can use a composite reliability whose values are $\geq 0.7$ and Cronbach's $\beta \geq 0.6$. Recapitulation of the results of the evaluation of validity and reliability can be seen in Table 1 .

Based on Table 1 it can be seen that the reflective indicator all the loading factor value $>0.6$ (Valid) and AVE value $>0.5$ (Valid) whereas from the reliability calculation shows that all composite reliability values $>0.7$ and cronbach's $\beta>0.6$. Thus, it can be concluded that all the latent variables have good and decent indicators.

Evaluation of the validity of the 2nd order model measurement model is done by looking at the estimation of the factor load. A variable is said to be validity if the standard factor load value is $\geq 0.6$. Recapitulation of the evaluation of the validity of the 2nd order model can be seen in Table 2 and 3. Based on the table above it can be seen that the reflective indicator of all loading factor values $>0.6$ (Valid). Thus, it can be concluded that all the latent variables have good and proper dimensions.
Table 2 : Validity and Reliability Evaluation Results

\begin{tabular}{|c|c|c|c|c|c|c|c|c|c|}
\hline \multirow{3}{*}{ Dimactis: } & \multirow{3}{*}{ inctions } & \multirow{2}{*}{\multicolumn{2}{|c|}{ 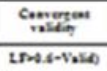 }} & \multirow{3}{*}{ i. } & \multirow{2}{*}{\multicolumn{2}{|c|}{ 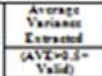 }} & \multirow{3}{*}{ 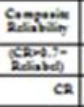 } & \multirow{3}{*}{ 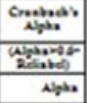 } & \multirow{3}{*}{ tath } \\
\hline & & & & & & & & & \\
\hline & & Lewe & Sa & & Avz & iath & & & \\
\hline $\operatorname{mon}^{2}$ & 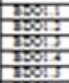 & 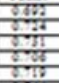 & $\frac{\text { ma }}{\text { min }}$ & $\frac{1}{2}$ & os:? & ved & 0.42 & 0.4 & 2eliatie \\
\hline Compriestien & 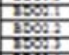 & $\frac{94}{671}$ & vul & $\frac{3}{2}$ & osm & ved & 0.404 & 0.624 & 2ellitit \\
\hline hinnent & $\frac{1801}{18015}$ & 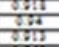 & min & $\frac{2}{1}$ & 0.48 & ver & 0.946 & 0.914 & 2eldit \\
\hline Anew on we & 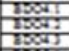 & 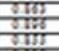 & 푤 & ? & 0.6 & ves & 0.003 & 0.462 & सालमान \\
\hline Oynimiges & 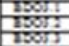 & 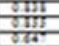 & min & Hיt & 0.617 & ves & 0.127 & 0.613 & साख्या \\
\hline Nating & 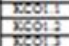 & $\frac{9118}{969}$ & एक & 2 & 0.400 & ves & 0.25 & 0.72 & mangh \\
\hline Opanar. & \begin{tabular}{|l|l|}
$x<021$ \\
$x \cos 2$
\end{tabular} & $\frac{960}{650}$ & जि & $\frac{1}{2}$ & 0.426 & ved & 0.004 & 0.70 & साख्रान \\
\hline cones & \begin{tabular}{|l|}
$x 6021$ \\
$x(60) 2$ \\
\end{tabular} & $\frac{6011}{6011}$ & $\begin{array}{l}\text { men } \\
\text { val }\end{array}$ & $\frac{1}{2}$ & 0.127 & ves & $0.91:$ & 0.504 & साख़ी \\
\hline 2oluting & \begin{tabular}{|l|}
$x 602 !$ \\
$x 6042$ \\
$x$
\end{tabular} & $\frac{6025}{603}$ & \begin{tabular}{|l}
$m$ \\
$y$
\end{tabular} & $\frac{1}{2}$ & $0.4: 6$ & ves & 0.400 & $0 . \% 4$ & 20mp \\
\hline 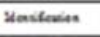 & 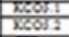 & $\frac{9171}{2101}$ & $\begin{array}{ll}\text { Ma } \\
y\end{array}$ & $\frac{1}{2}$ & $0.10:$ & ves & 0.418 & $0.45:$ & साल्या \\
\hline 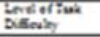 & 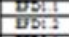 & $\frac{916}{67}$ & \begin{tabular}{|l|l|}
4 \\
4
\end{tabular} & $\frac{1}{2}$ & 0.103 & ved & 0.162 & 0.74 & साखो \\
\hline 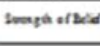 & 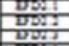 & $\frac{119}{919}$ & ma & 불 & 0.312 & ved & 0.205 & 0.624 & 2niman \\
\hline anming & 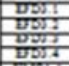 & 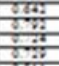 & 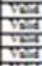 & i⿱ & 0.523 & ves & $0.8: 4$ & 0.604 & मान \\
\hline Cenivis & 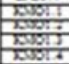 & 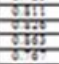 & 뇰 & i⿱⺌兀): & 0.664 & ves & 0.140 & 0.134 & 2eliath \\
\hline Tamentiph & 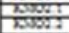 & 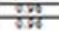 & 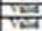 & 2 & $0.02:$ & ves & 0.050 & 0.914 & 20lith \\
\hline Dange & 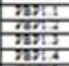 & 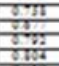 & $\begin{array}{l}\text { ma } \\
\text { mas }\end{array}$ & म्के & $0.5 n$ & ves & 0.144 & 0.44 & 2elidin \\
\hline 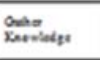 & 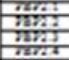 & 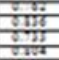 & मि & 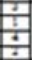 & $0.4: 6$ & ver & 0.465 & 0.92 & 2clidin \\
\hline 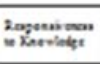 & 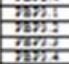 & 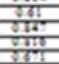 & iㅛㅁ & i: & o.ss: & veld & 0.428 & $0.72 t$ & 2elistie \\
\hline
\end{tabular}

Goodness of fit model: Goodness of fit model is used to determine the ability of endogenous variables to explain the diversity of exogenous variables or in other words to determine the magnitude of the contribution of exogenous variables to endogenous variables. Goodness of fit Model in PLS analysis is done using $\mathrm{R}^{2}$ and $\mathrm{Q}^{2}$ predictive relevance (Q2) (Table 4).

$\mathrm{R}^{2}$ variable of organizational commitment is 0.466 (46.6\%). This can indicate that the diversity of organizational commitment variables can be explained by 
J. Eng. Applied Sci., 15 (2): 398-409, 2020

Table 3: Validity results of 2nd order models

\begin{tabular}{|c|c|c|c|}
\hline \multirow[b]{2}{*}{ Dimension/Indicator } & \multicolumn{2}{|l|}{$\begin{array}{l}\text { Convergent } \\
\text { LF }>0.6=\text { valid }\end{array}$} & \multirow[b]{2}{*}{ Ranking } \\
\hline & Loading factor & Info & \\
\hline \multicolumn{4}{|l|}{ Organizational culture } \\
\hline Interpersonal trust & 0.652 & Valid & 4 \\
\hline Communication & 0.605 & Valid & 5 \\
\hline Information system & 0.742 & Valid & 3 \\
\hline Award system & 0.801 & Valid & 2 \\
\hline Organizational structure & 0.830 & Valid & 1 \\
\hline \multicolumn{4}{|l|}{ Organizational trust } \\
\hline Ability & 0.808 & Valid & 2 \\
\hline Openness & 0.822 & Valid & 1 \\
\hline Reliablity & 0.802 & Valid & 3 \\
\hline Concern & 0.766 & Valid & 4 \\
\hline Identification & 0.729 & Valid & 5 \\
\hline \multicolumn{4}{|l|}{ Self-efficacy } \\
\hline Level of task difficulty & 0.792 & Valid & 3 \\
\hline Strength of belief & 0.857 & Valid & 1 \\
\hline Generality & 0.836 & Valid & 2 \\
\hline \multicolumn{4}{|l|}{ Organizational commitment } \\
\hline Affective commitment & 0.895 & Valid & 1 \\
\hline Sustainable commitment & 0.895 & Valid & 2 \\
\hline \multicolumn{4}{|l|}{ Knowledge sharing behavior } \\
\hline Sharing knowledge & 0.834 & Valid & 2 \\
\hline Gather knowledge & 0.817 & Valid & 3 \\
\hline Responsiveness to knowledge & 0.915 & Valid & 1 \\
\hline
\end{tabular}

Table 4: Results of the goodness of fit model

\begin{tabular}{lll}
\hline Variables & $\mathrm{R}^{2}$ & $\mathrm{Q}^{2}$ \\
\hline Organizational commitment & 0.466 & 0.470 \\
knowledge sharing behavior & 0.315 & 0.380 \\
\hline
\end{tabular}

organizational culture, organizational trust and selfefficacy by $46.6 \%$ or in other words the contribution of organizational culture, organizational trust and self-efficacy to organizational commitment by $46.6 \%$ while the remaining amount is $53.4 \%$ is the contribution of other variables not addressed in this study. Then the $\mathrm{Q}^{2}$ variable of organizational commitment is worth 0.470 . This shows that organizational culture, organizational trust and self-efficacy have strong predictive power towards organizational commitment.

$\mathrm{R}^{2}$ variable of knowledge sharing behavior is 0.315 (31.5\%). This can indicate that the diversity of variables of knowledge sharing behavior can be explained by organizational culture, organizational trust, self-efficacy and organizational commitment by $31.5 \%$, or in other words the contribution of organizational culture, organizational trust, self-efficacy and organizational commitment to knowledge sharing behavior amounting to $31.5 \%$ while the remaining $68.5 \%$ is the contribution of other variables not addressed in this study. Then $\mathrm{Q}^{2}$ variable knowledge sharing behavior is 0.380 . This shows that organizational culture, organizational trust, self-efficacy and organizational commitment have strong predictive power towards knowledge sharing behavior. The goodness of fit model can also be seen through the $\mathrm{R}^{2}$ and $\mathrm{Q}^{2}$ can also be seen through the fit and quality indices model as shown in Table 5.
Table 5: Fit and quality indices models

\begin{tabular}{|c|c|c|}
\hline Model fit and quality indices & Results & Criteria \\
\hline $\begin{array}{l}\text { Average Path Coefficient } \\
\text { (APC) }\end{array}$ & $\begin{array}{l}0.228 \\
p<0.001\end{array}$ & $\begin{array}{l}\mathrm{p} \text {-value < level of } \\
\text { significance }(5 \%)\end{array}$ \\
\hline Average R-Squared (ARS) & $\begin{array}{l}0.391 \\
p<0.001\end{array}$ & $\begin{array}{l}\mathrm{p} \text {-value < level of } \\
\text { significance }(5 \%)\end{array}$ \\
\hline Average A djusted & 0.383, & p-value $<$ level of \\
\hline R-Squared(AARS) & $\mathrm{p}<0.001$ & significance (5\%) \\
\hline Average bolck VIF (AVIF) & 1.776 & $\begin{array}{l}\text { Acceptable if }<=5 \text {, } \\
\text { ideally }<=3.3\end{array}$ \\
\hline $\begin{array}{l}\text { Average Full collinearity } \\
\text { VIF (AVIF) }\end{array}$ & 1.832 & $\begin{array}{l}\text { Acceptable if }<=5 \text {, } \\
\text { ideally }<=3.3\end{array}$ \\
\hline Tenenhaus GoF (GoF) & 0.513 & $\begin{array}{l}\text { Small }>=0.1, \\
\text { medium }>=0.25, \\
\text { large }>=0.36\end{array}$ \\
\hline $\begin{array}{l}\text { Sympson's Paradox } \\
\text { Ratio (SPR) }\end{array}$ & 0.857 & $\begin{array}{l}\text { Acceptable if }>=0.7 \text {, } \\
\text { ideally }=1\end{array}$ \\
\hline $\begin{array}{l}\text { R-Squared Contribution } \\
\text { Ratio (RSCR) }\end{array}$ & 0.962 & $\begin{array}{l}\text { Acceptable if }>=0.9 \text {, } \\
\text { ideally }=1\end{array}$ \\
\hline $\begin{array}{l}\text { Statistical Suppression } \\
\text { Ratio (SSR) } \\
\end{array}$ & 1.000 & Acceptable if $>=0.7$ \\
\hline
\end{tabular}

Based on the results in the table it is known that the Average Path Coefficient (APC) index, Average $\mathrm{R}^{2}$ (ARS) and Average Adjusted $\mathrm{R}^{2}$ (AARS) produce $\mathrm{p}$ value of $<0.001$. This shows that the $\mathrm{p}$-value is smaller than the level of significance (5\%). Thus, based on the Average Path Coefficient (APC) index, average $\mathrm{R}^{2}$ (ARS) and average adjusted $\mathrm{R}^{2}$ (AARS) the PLS model in this study is acceptable.

Next the Average Block VIF (AVIF) and Average full collinearity VIF (AFVIF) indices produce values of 1,776 and 1,832 . This shows that the value is smaller than 5. Thus, based on the average block VIF (AVIF) index and the Average Full collinearity VIF (AFVIF) PLS Model in this study can be accepted or in other words the PLS Model in this study does not contain multicollinearity.

Sympson's Paradox Ratio (SPR) and Statistical Suppression Ratio (SSR). This shows that the value is $>0.7$. And the R-Squared Contribution Ratio (RSCR) index produces a value of $0.962(>0.9)$. Thus, based on Sympson's Paradox Ratio (SPR), Statistical Suppression Ratio (SSR) and R-Squared Contribution Ratio (RSCR) the PLS Model in this study can be accepted. The Tenenhaus GoF (GoF) index produces a value of 0.513 . This shows that the value is $>0.36$. Thus, based on the Tenenhaus GoF (GoF) index, the PLS Model in this study is stated to have high/strong predictive power.

Structural models and research hypothesis testing: The structural model relates to the evaluation of the coefficients or parameters that show a causal relationship or the influence of one latent variable on other latent variables. From the PLS output Model and hypothesis is done by looking at the estimated value of the path coefficient and the probability value (p-value) which is significant if the value is less then and eqal level of significance (alpha $(\alpha)=5 \%$ ). Based on the conceptual 


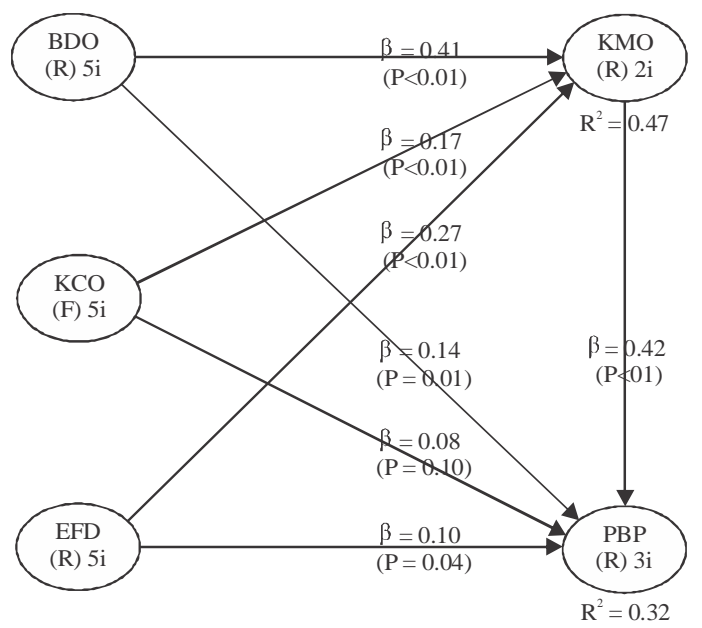

Fig. 2: Results of research path analysis

Table 6: Hypothesis testing and direct influence path coefficients

\begin{tabular}{llccll}
\hline Independent & Dependent & $\begin{array}{c}\text { Path } \\
\text { coefficient }\end{array}$ & SE & p-values & Conclusion \\
\hline BDO & KMO & 0.414 & 0.057 & $<0.001$ & Support \\
KCO & KMO & 0.172 & 0.059 & 0.002 & Support \\
EFD & KMO & 0.270 & 0.058 & $<0.001$ & Support \\
BDO & PBP & 0.136 & 0.060 & 0.012 & Support \\
KCO & PBP & -0.079 & 0.060 & 0.097 & Not support \\
EFD & PBP & 0.105 & 0.060 & 0.041 & Support \\
KMO & PBP & 0.420 & 0.057 & $<0.001$ & Support \\
\hline
\end{tabular}

framework of the study, testing the relationship model and hypothesis between variables was carried out with two stages: testing the direct influence path coefficient, testing the path coefficient of indirect influence. Both stages can be explained in Fig. 2.

Testing of path coefficients and direct influence hypotheses: Hypothesis testing and direct influence path coefficients are presented in Table 6.

- $\mathrm{H}_{1}$ : Organizational culture influences knowledge sharing behavior

The influence of organizational culture on knowledge sharing behavior results in a p-value of 0.012 . The test results show p-value less then level of significance (alpha $(\alpha=5 \%)$ ). This shows that there is a significant influence of organizational culture on knowledge sharing behavior. Path coefficient of organizational culture influence on knowledge sharing behavior of 0.136 shows that organizational culture has a positive effect on knowledge sharing behavior. This means that the stronger the organizational culture, the more likely it is to increase knowledge sharing behavior.

- $\mathrm{H}_{2}$ : Organizational trust influences knowledge sharing behavior
The influence of organizational trust on knowledge sharing behavior results in a p-value of 0.097 . The test results show p-value less then level of significance $(\alpha(\alpha=5 \%))$. This shows that there is an insignificant effect of organizational trust on knowledge sharing behavior. The path coefficient of the influence of organizational trust on knowledge sharing behavior of -0.079 shows organizational trust has a negative effect on knowledge sharing behavior. This means that the stronger the organizational trust, the more likely it is to reduce knowledge sharing behavior.

- $\mathrm{H}_{3}$ : self efficacy affects knowledge sharing behavior

The effect of self-efficacy on knowledge sharing behavior results in a p-value of 0.041 . The test results show $\mathrm{p}$-value less then level of significance $(\alpha(\alpha=5 \%))$. This shows that there is a significant effect of self-efficacy on knowledge sharing behavior. Path coefficients of the effect of self-efficacy on knowledge sharing behavior of 0.105 indicate that self-efficacy has a positive effect on knowledge sharing behavior. This means that stronger self-efficacy tends to increase knowledge sharing behavior.

- $\mathrm{H}_{4}$ : Organizational culture influences organizational commitment

The influence of organizational culture on organizational commitment results in a p-value of $<0.001$. The test results show p-value less then level of significance (Alpha $(\alpha=5 \%)$ ). This shows that there is a significant influence of organizational culture on organizational commitment. Path coefficients influence organizational culture on organizational commitment of 0.414 indicating that organizational culture has a positive effect on organizational commitment. This means that the stronger the organizational culture, the more likely it can be to increase organizational commitment.

- $\mathrm{H}_{5}$ : Organizational trust influences organizational commitment

The influence of organizational trust on organizational commitment results in a p-value of 0.002 . The test results show p-value less then level of significance $(\alpha(\alpha=5 \%))$. This shows that there is a significant influence of organizational trust on organizational commitment. The path coefficients of the influence of organizational trust on organizational commitment of 0.172 indicate that organizational trust has a positive effect on organizational commitment. This means that the stronger organizational trust is likely to increase organizational commitment. 
J. Eng. Applied Sci., 15 (2): 398-409, 2020

Table 7: Hypothesis testing and indirect influence path coefficient

\begin{tabular}{lllcll}
\hline Independent & Mediation & Dependent & $\begin{array}{c}\text { Indirect } \\
\text { coefficient }\end{array}$ & SE & p-values \\
\hline BDO & KMO & PBP & 0.174 & 0.042 & $<0.001$ \\
KCO & KMO & PBP & 0.072 & 0.043 & 0.046 \\
EFD & KMO & PBP & 0.114 & 0.042 & 0.004 \\
\hline
\end{tabular}

- $\mathrm{H}_{6}$ : Self-efficacy affects organizational commitment

The effect of self-efficacy on organizational commitment results in a p-value of $<0.001$. The test results show p-value less then level of significance (Alpha $(\alpha=5 \%)$ ). This shows that there is a significant effect of self-efficacy on organizational commitment. The path coefficient of the effect of self-efficacy on organizational commitment of 0.270 shows that self-efficacy has a positive effect on organizational commitment. This means that stronger self-efficacy tends to increase organizational commitment.

- $\mathrm{H}_{7}$ : Organizational commitment influences knowledge sharing behavior

The influence of organizational commitment on knowledge sharing behavior produces p-value of $<0.001$. The test results show p-value less then level of significance (Alpha $(\alpha=5 \%)$ ). This shows that there is a significant influence on organizational commitment to knowledge sharing behavior. The path coefficient of the influence of organizational commitment on knowledge sharing behavior of 0.420 shows organizational commitment has a positive effect on knowledge sharing behavior. This means that the stronger the organizational commitment, the more likely it is to increase knowledge sharing behavior.

Hypothesis testing and indirect influence path coefficient: Hypothesis testing and indirect path influence coefficients are presented in Table 7. The influence of organizational culture on knowledge sharing behavior through organizational commitment results in a p-value of $<0.001$. The test results show p-value less then level of significance (Alpha $(\alpha=5 \%)$ ). This shows that there is a significant influence of organizational culture on knowledge sharing behavior through organizational commitment. The path coefficient of the influence of organizational culture on knowledge sharing behavior through organizational commitment of 0.174 shows that organizational culture has a positive effect on knowledge sharing behavior through organizational commitment. This means that the higher organizational commitment caused by the stronger organizational culture, the more likely it is to increase knowledge sharing behavior.

The influence of organizational trust on knowledge sharing behavior through organizational commitment results in a p-value of 0.046 . The test results show p-value
Table 8: Dominant influences

\begin{tabular}{llc}
\hline Independent variables & Dependent variables & Total coefficient \\
\hline Organizational culture & Organizational commitment & 0.414 \\
Organizational trust & Organizational commitment & 0.172 \\
Self-efficacy & Organizational commitment & 0.270 \\
Organizational culture & Knowledge sharing behavior & 0.310 \\
Organizational trust & Knowledge sharing behavior & -0.006 \\
Self-efficacy & Knowledge sharing behavior & 0.218 \\
Organizational & Knowledge sharing behavior & 0.420 \\
commitment & & \\
\hline
\end{tabular}

less then level of significance $(\alpha(\alpha=5 \%))$. This shows that there is a significant influence of organizational trust on knowledge sharing behavior through organizational commitment. Path coefficients of the influence of organizational trust on knowledge sharing behavior through organizational commitment of 0.072 indicate organizational trust has a positive effect on knowledge sharing behavior through organizational commitment. This means that the higher the organizational commitment caused by the stronger organizational trust, the more likely it is to increase knowledge sharing behavior.

The effect of self-efficacy on knowledge sharing behavior through organizational commitment results in a $\mathrm{p}$-value of 0.004 . The test results show p-value less then level of significance (Alpha $(\alpha=5 \%)$ ). This shows that there is a significant effect of self-efficacy on knowledge sharing behavior through organizational commitment. The path coefficient of the effect of self-efficacy on knowledge sharing behavior through organizational commitment of 0.114 shows that self-efficacy has a positive effect on knowledge sharing behavior through organizational commitment. This means that the higher organizational commitment caused by stronger self-efficacy, the more likely it is to increase knowledge sharing behavior.

Dominant influence: Exogenous variables that have a dominant influence on endogenous variables can be known through the largest total coefficient Table 8.

\section{CONCLUSION}

The results of the analysis based on the table above inform the variables that have the greatest total coefficient of organizational commitment is the organizational culture with a total effect of 0.414 . Thus, organizational culture is the most influential variable or has the most dominant influence on organizational commitment.

Furthermore, the variables that have the greatest total coefficient on knowledge sharing behavior are organizational commitment with a total effect of 0.420 . Thus, organizational commitment is the most influential variable or has the most dominant influence on knowledge sharing behavior. 


\section{REFERENCES}

Aghaei, N., A. Ziaee and S. Shahrbanian, 2012. Relationship between organization culture and organizational commitment among employees of sport and youth head office of western provinces of Iran. Eur. J. Sports Exercise Sci., 1: 59-69.

Ahoozadeha, K. and N. Naderi, 2014. Study of the relationship between the organizational culture and knowledge sharing in the Lorestan Petrochemical Company. Indian J. Fundam. Appl. Life Sci., 4: 873-885.

Aizpurua, L.I., P.E.Z. Saldana and A.Z. Saldana, 2011. Learning for sharing: An empirical analysis of organizational learning and knowledge sharing. Int. Entrepreneurship Manage. J., 7: 509-518.

Akhtar, S., S. Ghayas and A. Adil, 2013. Self-efficacy and optimism as predictors of organizational commitment among bank employees. Int. J. Res. Stud. Psychol., 2: 33-42.

Al-Alawi, A.I., N.Y. Al-Marzooqi and Yasmeen F. Mohammed, 2007. Organizational culture and knowledge sharing: critical success factors. J. Knowl. Manage., 11: 22-42.

Anvari, R., N.N.A. Mansor, S.A.B.P.A. Rahman, R.H.B.A. Rahman and S.H. Chermahini, 2014. Mediating effects of affective organizational commitment and psychological contract in the relationship between strategic compensation practices and knowledge sharing. Procedia Soc. Behav. Sci., 129: 111-118.

Balay, R., 2012. Effect of learning organization perception to the organizational commitment: A comparison between private and public university. Educ. Sci. Theor. Pract., 12: 2474-2486.

Bandura, A., 1977. Social Learning Theory. Prentice Hall, New Jersey, USA., ISBN-13:9780138167516, Pages: 247.

Bandura, A., 1986. The explanatory and predictive scope of self-efficacy theory. J. Soc. Clin. Psychol., 4: 359-373.

Baruji, H.R., P. Lavaei, H. Namdar and L. Rostami, 2016. The role of organizational culture in encouraging employees to share knowledge. Int. J. Econom. Commerce Manage., 4: 454-467.

Bastug, G., A. Pala, M. Kumartasli, I. Gunel and M. Duyan, 2016. Investigation of the relationship between organizational trust and organizational commitment. Universal J. Educ. Res., 4: 1418-1425.

Bock, G.W. and Y.G. Kim, 2002. Breaking the myths of rewards: An exploratory study of attitudes about knowledge sharing. Inform. Resour. Manage. J., 15: 14-21.
Chang, W.J., S.H. Liao, Y.J. Lee and W.P. Lo, 2013. Organizational commitment, knowledge sharing and organizational citizenship behaviour: The case of the Taiwanese semiconductor industry. Knowl. Manage. Res. Pract., 13: 299-310.

Chen, C.C., 2011. Factors affecting high school teachers knowledge-sharing behaviors. Soc. Behav. Personality, 39: 993-1008.

Chen, S.S., Y.W. Chuang and P.Y. Chen, 2012. Behavioral intention formation in knowledge sharing: Examining the roles of KMS quality, KMS self-efficacy and organizational climate. Knowledge-Based Syst., 31: 106-118.

Chiu, C.M., M.H. Hsu and E.T. Wang, 2006. Understanding knowledge sharing in virtual communities: An integration of social capital and social cognitive theories. Decis. Support Syst., 42: 1872-1888.

Cropanzano, R. and M.S. Mitchell, 2005. Social exchange theory: An interdisciplinary review. J. Manage., 31: 874-900.

Dalkir, 2011. Becoming a Learning Organization. Addison-Wesley Publishing Company, Wokingham, England,.

Darroch, J., 2005. Knowledge management, innovation and firm performance. J. Knowl. Manage., 9: 101-115.

Davenport, T.H. and L. Prusak, 1998. Working Knowledge: How Organizations Manage What They Know. Harvard Business Press, Boston, MA., USA., ISBN-13: 9780875846552, Pages: 199.

De Vries, R.E., B. Van Den Hooff and J.A. De Ridder, 2006. Explaining knowledge sharing: The role of team communication styles, job satisfaction and performance beliefs. Commun. Res., 33: 115-135.

Detert, J.R., L.K. Trevino, E.R. Burris and M. Andiappan, 2007. Managerial modes of influence and counterproductivity in organizations: A longitudinal business-unit-level investigation. J. Appl. Psychol., 92: 993-1005.

Dirani, K.M., 2009. Measuring the learning organization culture, organizational commitment and job satisfaction in the Lebanese banking sector. Hum. Resour. Dev. Intl., 12: 189-208.

Fathi, N. M., U.C. Eze and G.G.G. Goh, 2011. Key determinants of knowledge sharing in an electronics manufacturing firm in Malaysia. Library Rev., 60: 53-67.

Folorunso, O.O., A.J. Adewale and S.M. Abodunde, 2014. Exploring the effect of organizational commitment dimensions on employees performance: An empirical evidence from Academic Staff of Oyo State Owned Tertiary Institutions, Nigeria. Int. J. Acad. Res. Bus. Soc. Sci., 4: 275-286. 
Ghina, A., 2012. The influence of corporate culture on organisational commitment: Case study of civil government organisations in Indonesia. Int. J. Basic Applied Sci., 1: 156-170.

Ghorbanhosseini, M., 2013. The effect of organizational culture, teamwork and organizational development on organizational commitment: The mediating role of human capital. Tehnicki Vjesnik, 20: 1019-1025.

Han, S.H., G. Seo, S.W. Yoon and D.Y. Yoon, 2016. Transformational leadership and knowledge sharing: Mediating roles of employee's empowerment, commitment and citizenship behaviors. J. Workplace Learn., 28: 130-149.

Hassandoust, F., L. Rajasvaran and M.F. Kazerouni, 2011. Behavioral factors influencing virtual knowledge sharing: Theory of reasoned action. J. Applied Res. Higher Edu., 3: 116-134.

Hislop, D., 2003. Linking human resource management and knowledge management via commitment: A review and research agenda. Employee Relat., 25: 182-202.

Ho, L.A., T.H. Kuo and B. Lin, 2012. How social identification and trust influence organizational online knowledge sharing. Internet Res., 22: 4-28.

Hofstede, 1994. Organizational Trust: Building Organizational Capablities. Wiley and Sons, New York, USA.,.

Holt, 2007. The impact of organizational commitment on knowledge sharing of employees. Pacific Bus. Rev. Int., 5: 1-10.

Hosseini, S.A., S.M. Bathaei and S. Mohammadzadeh, 2014. Does self-efficacy effect on knowledge sharing intention in e-learning system?: A motivational factor analysis in Open University Malaysia (OUM). Kuwait Chapter Arabian J. Bus. Manage. Rev., 3: 35-46.

Husain, Y.S., B. Sarita, D.T. Syarifuddin and Nurwati, 2015. The role of organizational learning culture to organizational citizenship behavior toward knowledge sharing behavior. Int. J.Sci. Res. (IJSR), 4: 642-648.

Iqbal, M.J., A. Rasli, L.H. Heng, M.B.B. Ali and I. Hassan et al., 2011. Academic staff knowledge sharing intentions and university innovation capability. Afr. J. Bus. Manage., 5: 11051-11059.

Islam, T., I. Ahmed and U.N.B.U. Ahmad, 2015. The influence of organizational learning culture and perceived organizational support on employee's affective commitment and turnover intention. Nankai Bus. Rev. Int., 6: 417-431.

Islam, T., U.K.S. Rehman, U.B.A.U. Norulkamar and I. Ahmed, 2013. Organizational learning culture and leader-member exchange quality: The way to enhance organizational commitment and reduce turnover intentions. Learn. Organization, 20: 322-337.
Islam, Z.M., I. Hasan, S.U. Ahmed and S.M. Ahmed, 2011. Organizational culture and knowledge sharing: Empirical evidence from service organizations. Afr. J. Bus. Manage., 5: 5900-5909.

Jain, K.K., M.S. Sandhu and S.K. Goh, 2015. Organizational climate, trust and knowledge sharing: Insights from Malaysia. J. Asia Bus. Stud., 9: 54-77.

Jaiswal, D. and R.L. Dhar, 2016. Impact of perceived organizational support, psychological empowerment and leader member exchange on commitment and its subsequent impact on service quality. Int. J. Prod. Perform. Manage., 65: 58-79.

Jo, S.J. and B.K. Joo, 2011. Knowledge sharing: The influences of learning organization culture, organizational commitment and organizational citizenship behaviors. J. Leadersh. Organizational Stud., 18: 353-364.

Joo, B.K. and S. Park, 2010. Career satisfaction, organizational commitment and turnover intention: The effects of goal orientation, organizational learning culture and developmental feedback. Leadersh. Organiz. Dev. J., 31: 482-500.

Kuo, T.H., 2013. How expected benefit and trust influence knowledge sharing. Ind. Manage. Data Syst., 113: 506-522.

Lin, H.F., 2007. Knowledge sharing and firm innovation capability: An empirical study. Int. J. Manpower, 28: 315-332.

Luthans, F., 2006. Organizational Behavior. 9th Edn., Erwin McGraw Hill, New York, USA.,.

Mack, O., A. Khare, A. Kramer and T. Burgartz, 2015. Managing in a VUCA World. Springer, Switzerland, ISBN: 978-3-319-16888-3, Pages: 251.

Mehrabi, J., M. Modiri, M. Sharifi and N. Mahdevar, 2013. The impact of organizational culture on knowledge Sharingin the executive organizations in the Guilan Province. Interdiscip. J. Contemp. Res. Bus., 5: 148-155.

Meyer, J.P. and N.J. Allen, 1991. A three-component conceptualization of organizational commitment. Hum. Resour. Manage. Rev., 1: 61-89.

Mitic, S., J. Vukonjanski, E. Terek, B. Gligorovic and K. Zoric, 2016. Organizational culture and organizational commitment: Serbian case. J. Eng. Manage. Competitiveness (JEMC), 6: 21-27.

Momeni, M., A.B. Marjani and V. Saadat, 2012. The relationship between organizational culture and organizational commitment in staff department of general prosecutors of Tehran. Int. J. Bus. Soc. Sci., 3: 217-217.

Moon, H. and C. Lee, 2014. The mediating effect of knowledge-sharing processes on organizational cultural factors and knowledge management effectiveness. Perform. Improv. Q., 26: 25-52. 
Muneer, S., J. Iqbal and C.S. Long, 2014. An incorporated structure of perceived organizational support, knowledge-sharing behavior, organizational trust and organizational commitment: A strategic knowledge management approach. Pak. J. Commerce Social Sci., 8: 42-57.

Nonaka, I. and H. Takeuchi, 1995. The Knowledge Creating Company: How Japanese Companies Create the Dynamics of Innovation. Oxford University Press, New York, ISBN: 0195092694, Pages: 284.

Nonaka, I., 1994. A dynamic theory of organizational knowledge creation. Organiz. Sci., 5: 14-37.

Ooi, K.B. and V. Arumugam, 2006. The influence of corporate culture on organizational commitment: Case study of semiconductor organizations in Malaysia. Sunway Acad. J., 3: 99-115.

Roberts, J., 2000. From know-how to show-how? Questioning the role of information and communication technologies in knowledge transfer. Technol. Anal. Strategic Manage., 12: 429-443.

Rutten, W., J. Blaas-Franken and H. Martin, 2016. The impact of (Low) trust on knowledge sharing. J. Knowl. Manage., 20: 199-214.

Sanjaghi, M.E., P. Akhavan and S. Najafi, 2013. Fostering knowledge sharing behavior: The role of organizational culture and trust. Fostering knowledge sharing behavior: The role of organizational culture and trust. Int. J. Acad. Organizational Behav. Manage., 2: 9-33.
Shaari, R., S.A.A. Rahman and A. Rajab, 2014. Self-efficacy as a determined factor for knowledge sharing awareness. Int. J. Trade Econom. Finance, 2: 39-42.

Shirazi, A., N. Shakoori, M.M.Y. Nejad and Z. Asemi, 2014. Examining the relationship between affective commitment and knowledge sharing and considering variables affecting thrust and cost of knowledge sharing. Int. J. Emerging Trends Eng. Dev., 4: 156-180.

Song, J.H. and J.A. Kolb, 2013. Learning organizational culture and firm performance the mediating effects of knowledge creation in Korean firms. J. Leadersh. Organizational Stud., 20: 252-264.

Swift, P.E. and A. Hwang, 2013. The impact of affective and cognitive trust on knowledge sharing and organizational learning. Learn. Organiz., 20: 20-37.

Ting, H., F. Chuah and E.C. de Run, 2016. Knowledge sharing behaviour in innovative working environment: A case of a software developing company. Int. Bus. Manage., 10: 1989-1997.

Tuan, 2016. How organizational culture nurtures knowledge sharing: The mediating role of public service motivation. J. Publ. Sect. Manage., 29: 91-108.

Yilmaz, R., 2016. Knowledge sharing behaviors in e-learning community: Exploring the role of academic self-efficacy and sense of community. Comput. Hum. Behav., 63: 373-382.

Zhang, P. and F.F. Ng, 2012. Attitude toward knowledge sharing in construction teams. Ind. Manage. Data Syst., 112: 1326-1347. 